5. Shavryn V. A., Avramenko Yu. N. Comparative morphometry of cerebral microvessels in atherosclerotic and diabetic encephalopathy. Morphologia. 2017. № 1. C. 58-61.

6. Levytskyi V. A., Zhurakivska O. Y., Tkachuk Y. L. Exenatide use for the correction of morphological changes of pituitary-adrenal system in experimental diabetes mellitus. The Pharma Innovation Journal. 2016. № 5. C. 76-80.

DOI https://doi.org/10.30525/978-9934-26-113-8-19

\title{
MORPHOLOGICAL CHANGES OF THE MYOCARDIUM IN COMORBID PATHOLOGY
}

\author{
Vasyliuk V. M. \\ Graduate student at the Department \\ of Clinical Anatomy and Operative Surgery \\ Ivano-Frankivsk National Medical University \\ Zhurakivska O. Ya. \\ Doctor of Medical Science, Professor, \\ Professor at the Department of Human Anatomy \\ Ivano-Frankivsk National Medical University \\ Ivano-Frankivsk, Ukraine
}

The prevalence of heart failure in the population ranges from 1 to $4 \%$, and in patients with diabetes mellitus (DM) it ranges from $12 \%$ in young people to $22 \%$ in people over 64 years [1]. According to the authors, almost a third of patients hospitalized with heart failure, have diabetes. Diabetic cardiomyopathy (DCMP) is diagnosed in approximately $4 \%$ of patients with type 1 diabetes at a young age, with a labile course, predisposition to ketoacidosis, low body weight and small vessel damage. DCMP has no specific clinical signs and often develops without subjective symptoms [2].

In view of the above, the aim of our research was to study the morphological changes in the myocardium of the heart of rats with streptozotocin-induced diabetes mellitus (SIDM) under chronic stress.

Material and Methods. The study used 15 adult white male rats (body weight $180-200 \mathrm{~g}$ ), which were equally divided into 3 groups: group 1 - rats with simulated SIDM and immobilization stress, group 2 - rats with SIDM, group 3 - intact animals. In groups 1 and 2, SIDM was simulated by a single 
intraperitoneal injection of streptozotocin «SIGMA» (USA), which was diluted in $0.1 \mathrm{M}$ citrate buffer with a $\mathrm{pH}$ of 4.5 (at the rate of $6 \mathrm{mg}$ per $100 \mathrm{~g}$ of body weight). In group 1, SIDM was simulated and starting from the $14^{\text {th }}$ day of the experiment chronic immobilization stress was simulated on a once-only basis by placing the animal in a closed plastic container for 5 hours a day. The material was taken on the $14^{\text {th }}$ day from the beginning of the experiment. Histological, electron microscopic, biochemical and statistical research methods were used. For morphometric studies, photographs of histological sections (field of view of the light microscope Leica DM750 was photographed using a digital camera ToupCam 5.2M UHCCD C-Mount Sony) and digitized electrograms were used. Morphometry was performed using ImageJ version 1.47t. Statistical analysis was carried out using the statistical package Stat.Soft.Inc; Tulsa, OK, USA; Statistica 10.

Result. On the $14^{\text {th }}$ day of the experiment, the level of glucose and glycated hemoglobin in the blood of rats of group 1 was the highest one, compared to group 3 and was $15.43 \pm 2.34 \mathrm{mmol} / \mathrm{l} \quad(\mathrm{p}<0.001)$ and $7.09 \pm 0.57 \%(\mathrm{p}<0.01)$, respectively; in group $2-13.65 \pm 2.29 \mathrm{mmol} / \mathrm{l}$ $(\mathrm{p}<0.001)$ and $6.31 \pm 0.57 \%(\mathrm{p}<0.01)$; in group 3 (intact rats) $-4.27 \pm 0.49$ $\mathrm{mmol} / \mathrm{l}$ and $2.24 \pm 0.17 \%$. Such biochemical changes in groups 1 and 2 indicate the development of decompensated diabetes.

On the $14^{\text {th }}$ day of the experiment in rats of groups 1 and 2, compared with intact animals, a decrease in the area of cardiomyocytes in different parts of the myocardium by $17.5-23.4 \%$ (in all cases, $\mathrm{p}<0.05$ ) was observed; at the same time the area of the nuclei did not change significantly (in all cases, $\mathrm{p}>0.05$ ). Some authors described a $30 \%$ decrease in cardiomyocyte volume on the $7-14^{\text {th }}$ days of the onset of streptozotocin-induced diabetes, explaining this by their shrinkage $[3,4]$. Other scientists believe that the decrease in the area of muscle fibers in skeletal muscle in SIDM is caused by the decrease in their glycogen content [5].

At the ultrastructural level, in the myocardium of rats of groups 1 and 2 , the violations of the mitochondrial ultrastructure were revealed from the disorganization of their cristae to their complete destruction and transformation into vacuoles. The volume density of mitochondria increased by $15-26.3 \% \quad(\mathrm{p}<0.05)$ compared with intact parameters, which can be considered as compensatory processes in response to hyperglycemia and hypoxia.

In rats of group 1 , already on the $14^{\text {th }}$ day of the development of comorbid pathology, the initial manifestations of diabetic microangiopathy were revealed; they were characterized by spasm of arterioles and vasodilation of the venous link of the hemomicrocirculatory flow, while in the capillaries 
hemorheological disorders were noted (erythrocyte sludge, adhesion of erythrocytes and platelets). Such changes are associated with increased levels of contrainsular hormones in the blood and activation of the renin-angiotensin system, which cause vasoconstriction and increase blood thrombogenic activity [6]. In rats of group 2, only in single microhemovessels the hemorheological disorders were found.

Thus, SIDM leads to the development of diabetic myocardial microangiopathy, which is manifested by: erythrocyte sludge in microhemovessels, spasm of the arterial link of the hemomicrocirculatory flow and venous dilation. These changes are more pronounced in comorbid pathology and lead to disruption of myocardial blood supply, and as a consequence - to vacuolar cardiomyocyte dystrophy.

\section{References:}

1. Chirag H. Mandavia, Anna R. Aroor, Vincent G. Demarko, James R. Sowers. Molecular and metabolic mechanisms of cardiac dysfunction in diabetes. Life Sci. 2013. Vol.92 №11. P. 601-608.

2. Trachanas K., Sideris S., Aggeli C., Poulidakis E., Gatzoulis K. Diabetic Cardiomyopathy: From Pathophysiology to Treatment. Hellenic J Cardiol. 2014. № 55. P. 411-421.

3. Cagalinec M, Waczulikova I, Ulicna O, Chorvat D JR. Morphology and Contractility of Cardiac Myocytes in Early Stages of StreptozotocinInduced Diabetes Mellitus in Rats. Physiol. Res. 2013. №62. P. 489-50.

4. Zhurakivska O. Y., Mykulets T. I., Dutchak U. M., Klypych Ya. I. Structural Changes of Endocrine System of Myocardium during the Streptozotocin Diabetes Mellitus. World of medicine and biology. 2018. № 1. P. 126-130.

5. Zhurakivska O. Ya., Koshkin O. Ye., Tkachuk Y. L., Rudyak O. M., Knyazevych-Chorna T. V. Age characteristics of morphogenesis of diabetic myopathies. Problems of endocrine pathology. 2020. №4. P. 115-123. doi: 10.21856/j-PEP. 2020. № 4. C. 15.

6. Zhurakivska O. Ya., Miskiv V. A., Tkachuk Yu. L., et al. Morphofunctional changes of the hypothalamic-pituitary-adrenal system in experimental diabetes mellitus. International research and practice conference "Innovative technology in medicine: experience of Poland and Ukraine»: Conference Proceedings, April 28-29, 2017. Lublin, 2017. P. 117-121. 